\title{
Effect of inhibition of Helicobacter pylori urease activity by acetohydroxamic acid on serum gastrin in duodenal ulcer subjects
}

\author{
A M El Nujumi, C A Dorrian, R S Chittajallu, W D Neithercut, K E L McColl
}

\begin{abstract}
The mechanism of the hypergastrinaemia associated with Helicobacter pylori infection is unknown. It may be an effect of the ammonia produced by the bacterium near the antral epithelial surface. We have examined the effect on serum gastrin of inhibiting $H$ pylori urease activity with acetohydroxamic acid in six duodenal ulcer patients. On day 1 the fasted patients received placebo tablets at $8 \mathrm{am}$, a peptide meal at $10 \mathrm{am}$, and a ${ }^{14} \mathrm{C}$ urea breath test at $11.30 \mathrm{am}$. The next day $750 \mathrm{mg}$ acetohydroxamic acid was administered orally in place of the placebo. The median (range) 30 minute breath test value (dose $/ \mathrm{mmol} \mathrm{CO}_{2} \times \mathrm{kg}$ body wt $\times 100)$ was $152(111-335)$ on day 1 , but only $22(14-95)$ the next day $(p<0.03)$. Further studies performed in one subject confirmed that acetohydroxamic acid lowered the ammonium concentration and raised the urea concentration in gastric juice. The inhibition of urease activity and ammonia production did not result in a fall in the basal gastrin concentration or in the median integrated gastrin response to the peptide meal, which was 78 ng/l.h (range 21-222) on day 1 and $79 \mathrm{ng} / \mathrm{l} . \mathrm{h}$ (33-207) the next day. Ten days after acetohydroxamic acid, the urea breath test values were similar to those before treatment. This study shows that the raised gastrin concentration in patients with $H$ pylori infection is not directly related to the organism's urease activity. It also shows that temporary suppression of $H$ pylori urease activity does not clear the infection.
\end{abstract}

Eradication of Helicobacter pylori infection of the gastric antrum results in a lowering of the circulating gastrin concentration. ${ }^{1-5}$ The fasting concentration falls by $27-33 \%$ and the integrated gastrin response to a meal by $30-58 \%$. This stimulation of gastrin release by $H$ pylori may be relevant to the organism's role in duodenal ulcer disease. The mechanism by which chronic infection of the antral mucosa with $H$ pylori results in increased gastrin release is not known.

$H$ pylori is remarkable because of its high urease activity by which it hydrolyses urea to ammonia and carbon dioxide. ${ }^{6}$ As a result of this, patients with the infection have reduced concentrations of urea and increased concentrations of ammonium in their gastric juice. ${ }^{5}$ The production of ammonia by the bacterium at the antral epithelial surface could increase gastrin release by any of three theoretical mechanisms. Ammonia is a strong alkali and could therefore prevent the physiological inhibition of gastrin release by gastric acid. ${ }^{7}$ In addition, an increase in the antral surface $\mathrm{pH}$ by ammonia would facilitate the entry of dietary amines into the antral G cells and thereby their stimulation of gastrin release. ${ }^{8}$ Thirdly, ammonia could stimulate gastrin release directly, as has been shown to occur in the rat. ${ }^{9}$

In an attempt to elucidate the mechanism of the hypergastrinaemia associated with $H$ pylori infection, we have examined the effect of inhibiting the bacterium's urease activity and ammonia production on serum gastrin in duodenal ulcer patients.

\section{Patients and methods}

STUDIES IN PATIENTS WITH $H$ PYLORI INFECTION Six patients confirmed endoscopically to have duodenal ulceration within the previous year but currently in clinical remission were studied. Their median age was 39 years (range 26-52) and three were women. In each patient, an antral biopsy specimen obtained endoscopically within the preceding three months had shown gastritis associated with $H$ pylori like organisms.

The patients reported fasted and a venous blood sample was removed at 8 am for gastrin determination. Immediately after this they drank $50 \mathrm{ml}$ water and further blood samples were taken at 30 minute intervals for two hours. At $10 \mathrm{am}$ they took a standard meal consisting of two beef cubes (OXO Ltd, Croydon, England) dissolved in $200 \mathrm{ml}$ water at $50^{\circ} \mathrm{C}$. Further blood samples were taken at 10 minute intervals for 70 minutes and a final one at 90 minutes after the OXO drink. Immediately after this sample a ${ }^{14} \mathrm{C}$ urea breath test was performed to measure $H$ pylori urease activity. For this they drank 250 ml Ensure Plus (Abbott Laboratories, England) to delay gastric emptying, followed by $0.4 \mathrm{MBq}$ ${ }^{14} \mathrm{C}$ urea (Amersham International) in $25 \mathrm{ml}$ water. Breath samples for ${ }^{14} \mathrm{C}-\mathrm{CO}_{2}$ analysis were obtained at 10 minute intervals for 90 minutes.

The next day, the study was repeated in an identical fashion except that the patients received $750 \mathrm{mg}$ acetohydroxamic acid (Lithostat, Mission Pharmacol, USA) with a 50 ml drink of water at 8 am.

Ten days later a third ${ }^{14} \mathrm{C}$ urea breath test was performed to determine whether the temporary inhibition of urease activity had resulted in clearance of the infection.

STUDIES IN PATIENTS WITHOUT H PYLORI INFECTION

Two male patients (aged 25 and 52 years) with a

\author{
Dr K E L McColl, University \\ Department of Medicine and \\ Therapeutics, Gardiner \\ Institute, Western Infirmary, \\ Glasgow G11 6NT. \\ Accepted for publication \\ 17 September 1990 \\ of Medicine and \\ Pathological \\ C A Dorrian \\ S Chittajallu \\ W D Neithercut
}




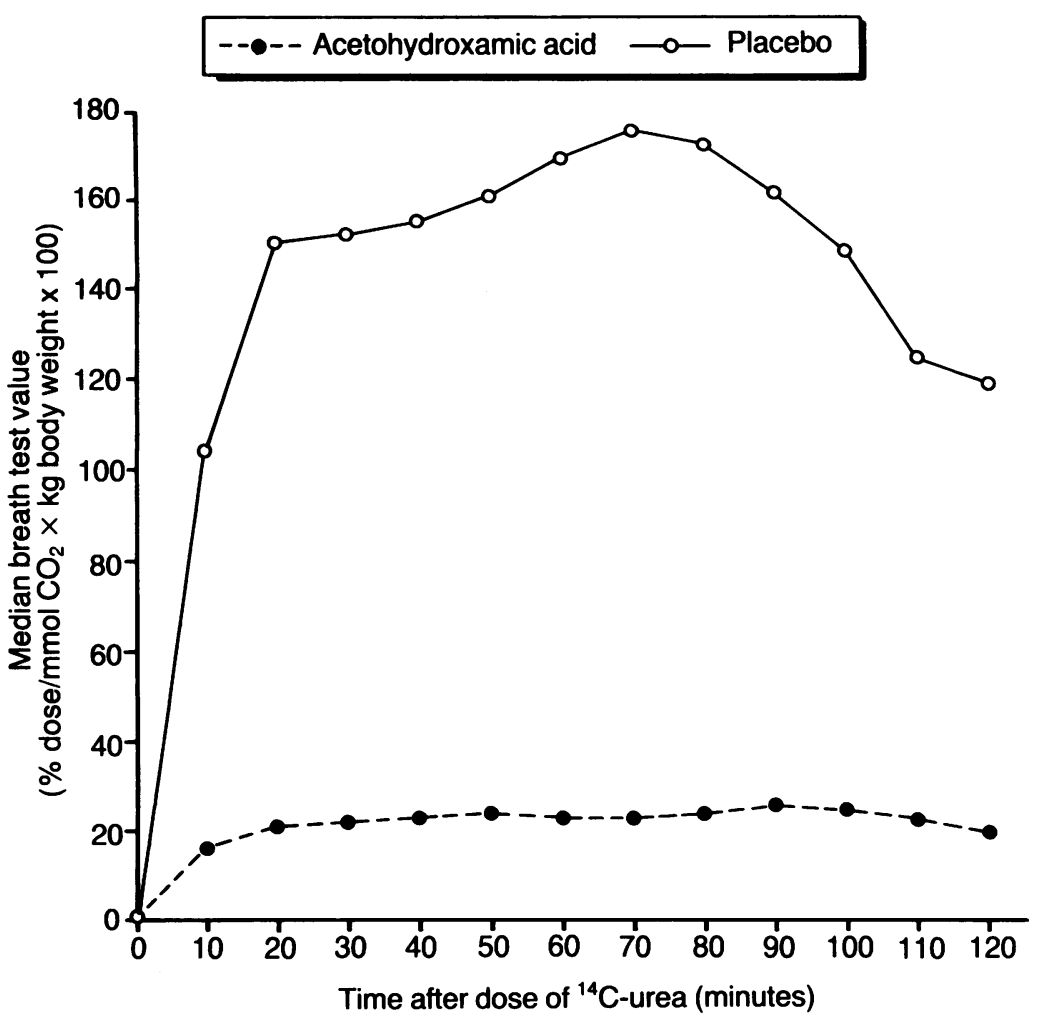

Figure 1: Effect of acetohydroxamic acid on Helicobacter pylori urease activity assessed by the ${ }^{14} \mathrm{C}$ urea breath test. The values are medians of six patients.

past history of duodenal ulcer disease, but in whom $H$ pylori had been eradicated within the previous year, were studied in an identical fashion to that described above. This was performed in order to exclude the possibility that acetohydroxamic acid might have a direct effect on gastrin release.

STUDY IN A HEALTHY VOLUNTEER WITH $H$ PYLORI INFECTION

The effect of acetohydroxamic acid on the con-

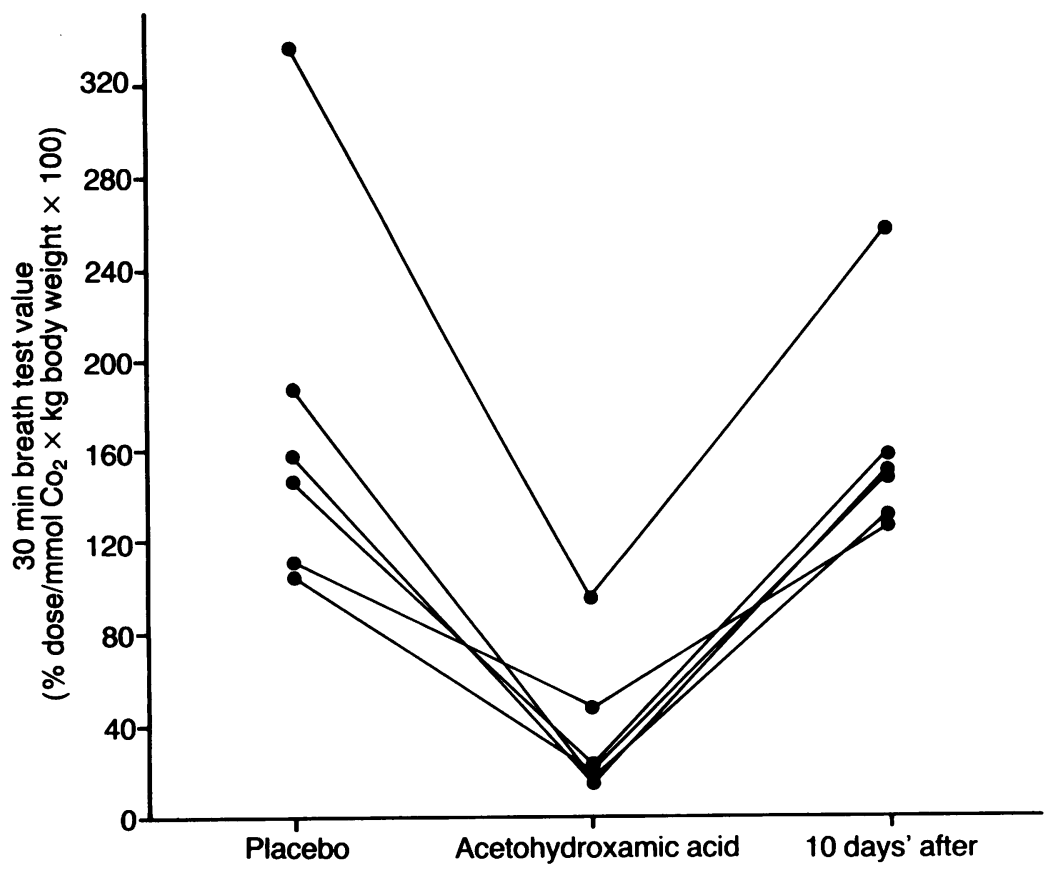

Figure 2: Subjects 30 minute ${ }^{14} \mathrm{C}$ urea breath test values on placebo, $3 \cdot 5$ hours after single 750 mg dose of acetohydroxamic acid, and 10 days later. centrations of urea and ammonium in gastric juice was examined in a single healthy volunteer (AN, aged 32 years) with $H$ pylori infection. Endoscopic antral biopsy specimen obtained three months earlier had shown gastritis and $H$ pylori like organisms. The ${ }^{14} \mathrm{C}$ urea breath test performed one month before the study gave a 30 minute value of $109 \%$ dose $/ \mathrm{mmol} \mathrm{CO}_{2} \times \mathrm{kg}$ body wt $\times 100$ which is in the middle of our range for infected subjects (35-225).

He reported fasted at 8 am and a nasogastric tube was passed perorally. The resting gastric juice was aspirated and discarded and then constant suction applied. At 30 minutes the suction was temporarily stopped and a $5 \mathrm{ml}$ sample of gastric juice was obtained by manual aspiration. A further such sample was obtained at 60 minutes. Immediately after this $750 \mathrm{mg}$ acetohydroxamic acid was taken orally with 50 $\mathrm{ml}$ water and no suction was applied until one hour later when all the resting volume was aspirated and a $5 \mathrm{ml}$ aliquot retained for analyses. Suction was then recommenced but temporarily stopped every 30 minutes over the following three and a half hours to allow manual aspiration of $5 \mathrm{ml}$ samples of gastric juice.

\section{ANALYSES}

Serum gastrin concentrations were determined by a standard radioimunoassay kit (CIS UK Ltd). Each patient's day 1 and day 2 samples were assayed in the same batch. The concentration of urea in gastric juice was determined by a prospective analyser (American Monitor, West Sussex, UK) and the concentration of ammonium by an enzymatic method (Sigma, Dorset, UK). Preliminary studies confirmed that acetohydroxamic acid did not interfere with the analysis of urea or ammonium in gastric juice. The integrated gastrin response to the OXO meal was assessed by calculating the area under the serum gastrin concentration time curve using the trapezoid method.

Statistical analysis was performed by means of the Wilcoxon signed rank sum test. The study was approved by the Western Infirmary Ethical Committee and each patient gave written informed consent.

\section{Results}

The excretion of ${ }^{14} \mathrm{C}-\mathrm{CO}_{2}$ in the breath was considerably lower after the administration of acetohydroxamic acid (Fig 1). On the first study day, the median 30 minute breath test value was $152 \%$ dose $/ \mathrm{mmol} \mathrm{CO}_{2} \times \mathrm{kg}$ body wt $\times 100$ (range 111-335) compared with a value of 22 (range 14 95) after acetohydroxamic acid $(p<0.03)$. The median value 10 days after the administration of acetohydroxamic acid was 149 (range 126-257) which was similar to the pretreatment value (Fig 2).

In spite of the noticeable suppression of $H$ pylori urease activity, there was no difference between the two study days with respect to the basal or meal stimulated serum gastrin concentrations (Fig 3). The median integrated gastrin response to the OXO meal was $78 \mathrm{ng} / \mathrm{l} . \mathrm{h}$ 


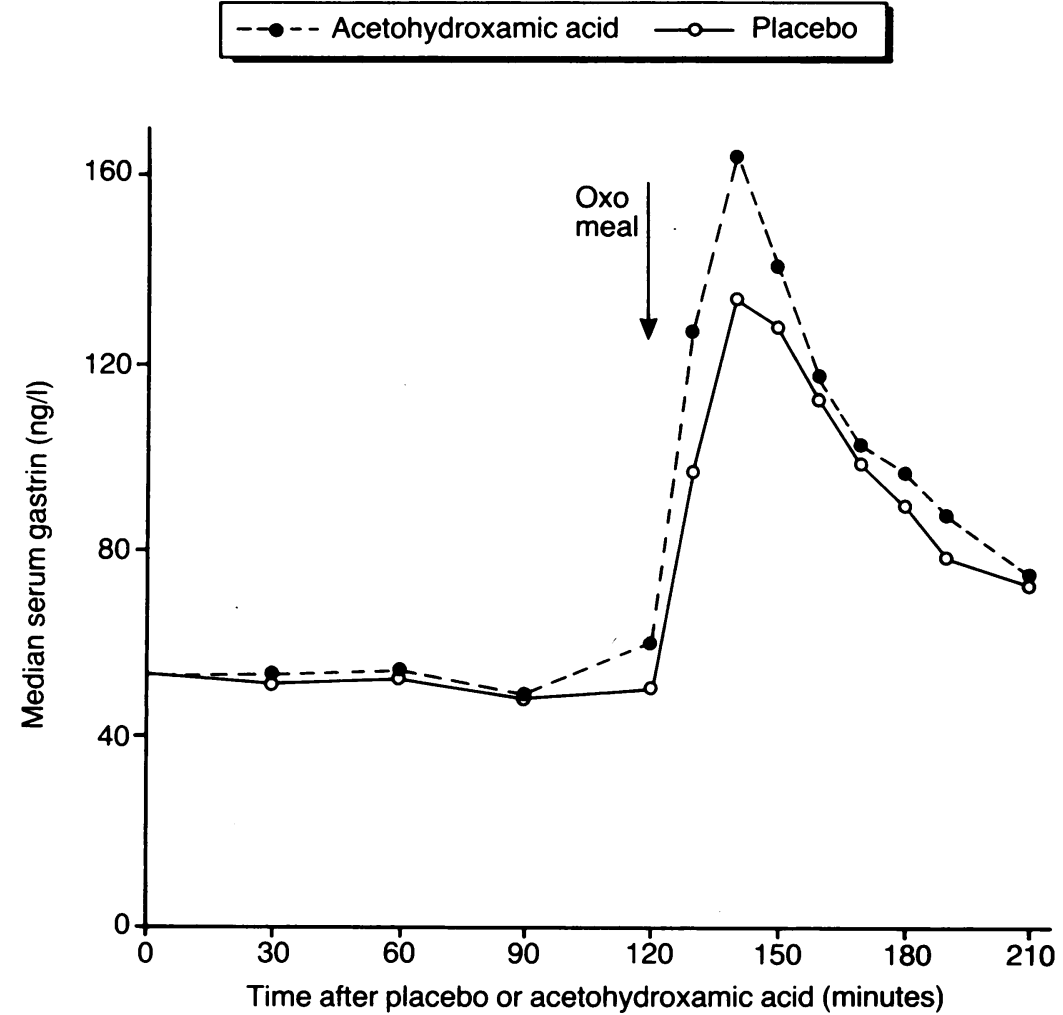

Figure 3: Basal and meal stimulated serum gastrin concentrations on placeo and after $750 \mathrm{mg}$ acetohydroxamic acid. The values are medians of six patients.

(range 21-222) on day 1 and 79 (range 33-207) on day 2 (Fig 4).

In the two patients without $H$ pylori infection, basal and meal stimulated gastrin values were also unaffected by the acetohydroxamic acid.

In the healthy volunteer with $H$ pylori infection, the administration of acetohydroxamic acid resulted in a rise in the urea concentration and a fall in the ammonium concentration in gastric juice (Fig 5). This was evident in the first sample

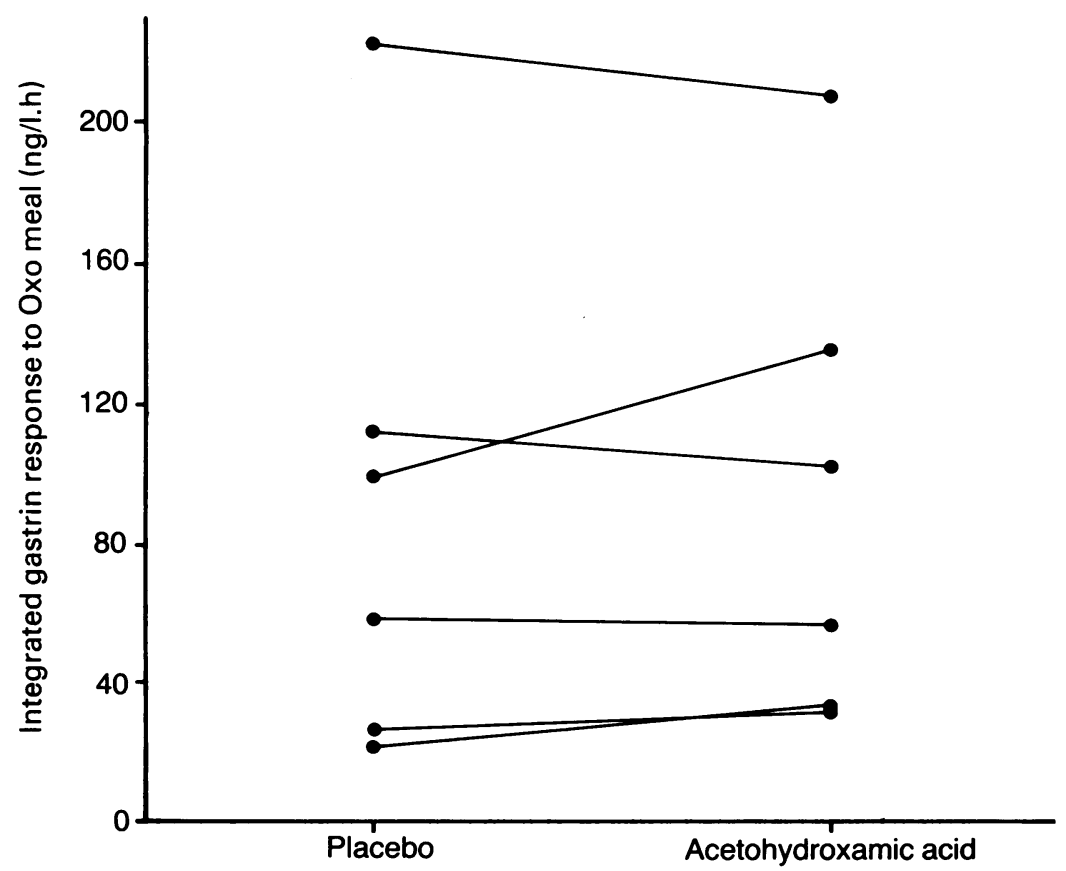

Figure 4: Subjects integrated gastrin response to the $O X O$ meal on placebo and acetohydroxamic acid. of juice, collected one hour after the administration of the urease inhibitor, and persisted for the full three and a half hours studied. The ammonium concentrations in gastric juice before the inhibitor were 5.2 and $5.5 \mathrm{mmol} / \mathrm{l}$ and values after the inhibitor ranged from $1.9-3.6 \mathrm{mmol} / \mathrm{l}$. The ratio of urea:ammonium in gastric juice before the urease inhibitor was 0.2 whereas after the inhibitor five of the six patients showed values more than $1 \cdot 0$.

None of the patients experienced any side effects after the administration of acetohydroxamic acid.

\section{Discussion}

Acetohydroxamic acid is a specific urease inhibitor that has been used to reduce bacterial ammonia production in patients with renal calculi secondary to chronic urinary tract infection. ${ }^{10}$ Reducing the ammonia production lowers the $\mathrm{pH}$ of the urine and thereby lessens the tendency for calculi formation. In these patients the drug has been prescribed in a dose of $250 \mathrm{mg}$ four times a day. We administered the drug as a once off dose of $750 \mathrm{mg}$ in order to achieve rapid and effective inhibition of urease activity.

Inhibition of $H$ pylori urease activity was shown by the fivefold reduction in the $\mathbf{3 0}$ minute values of the ${ }^{14} \mathrm{C}$ urea breath test. The concentrations of urea and ammonium in the gastric juice of the volunteer also confirmed inhibition of urease activity. We have previously noted that though there is overlap of $H$ pylori negative and positive subjects with respect to their gastric juice ammonium concentration, the urea :ammonium ratio in gastric juice provides clear separation of the two groups." The median urea:ammonium ratio before the urease inhibitor was $0 \cdot 2$, which is within our range for infected subjects $(0.04-0.7)$, and that after administration of the inhibitor was 1.2 which is just within our range for patients in whom the infection has been eradicated $(1 \cdot 1-113)$. The finding of altered urea and ammonium concentrations in the first sample of juice examined and its persistence throughout the remainder of the three and a half hours observed is consistent with the fact that acetohydroxamic acid is rapidly absorbed from the upper gastrointestinal tract reaching peak plasma concentrations at 60 minutes and has a plasma half life of three and a half to five hours. ${ }^{12}$ It is not clear whether the inhibition of $H$ pylori urease activity by oral acetohydroxamic acid is the result of a topical or systemic effect, or both.

In spite of the suppression of $H$ pylori urease activity there was no accompanying fall in the basal gastrin concentration or in the gastrin response to the OXO meal. There was also no change in gastrin concentration in the $H$ pylori negative subjects, which excluded the possibility that a fall in gastrin in those with the infection had been masked by a direct gastrin stimulating effect of the drug.

It has been proposed that the hypergastrinaemia in patients with $H$ pylori infection is caused by the ammonia produced by the bacterium raising the antral surface $\mathrm{pH} \cdot{ }^{13}$ This would prevent the physiological suppression of gastrin 

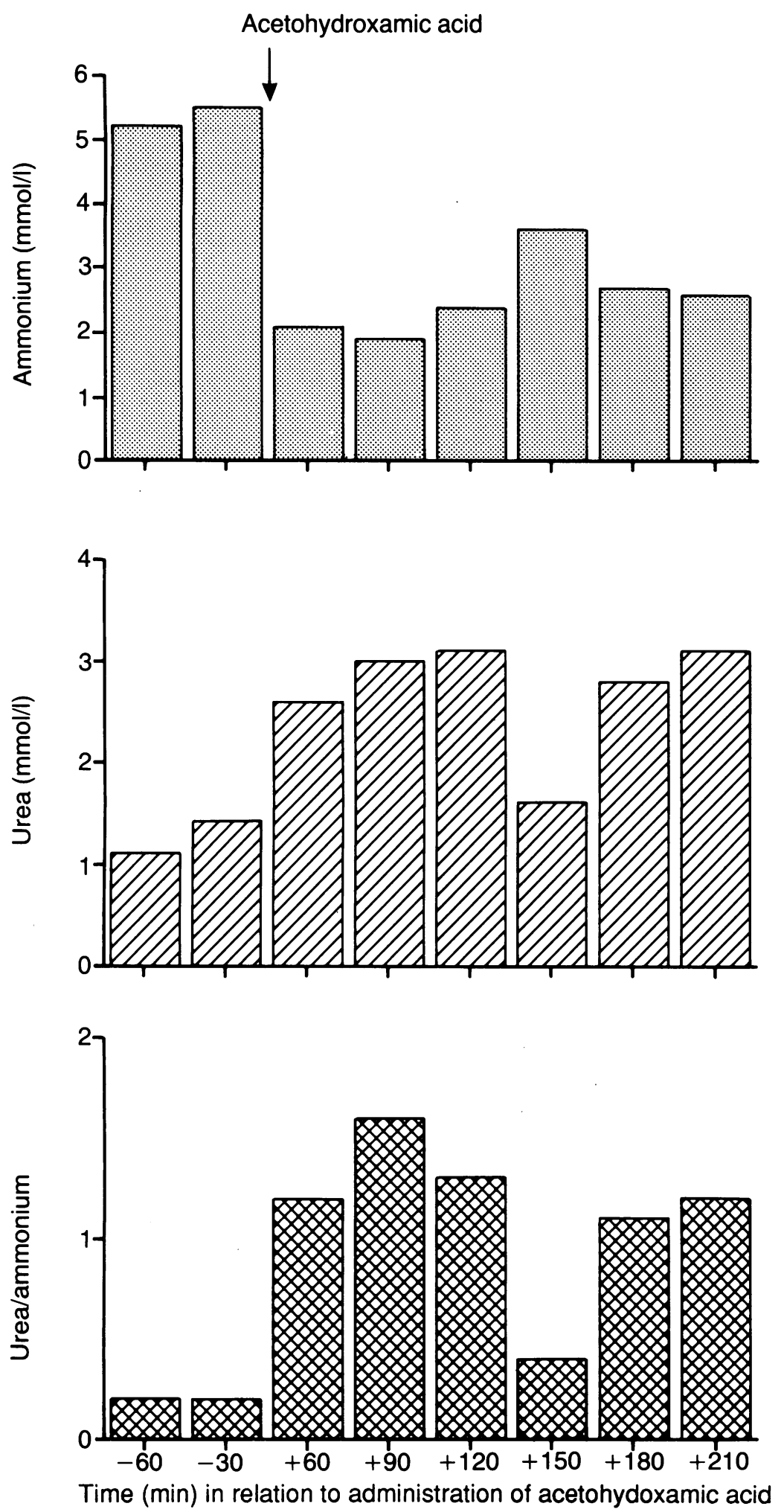

Figure 5: Effect of 750mg acetohydroxamic acid on gastric juice concentrations of ammonium and urea and their ratio in healthy volunteers with Helicobacter pylori infection.

release by intragastric acid, resulting in inappropriate release of the hormone. If this were the mechanism of the hypergastrinaemia, the gastrin concentration should fall rapidly after inhibition of bacterial urease activity. In patients with hypergastrinaemia secondary to achlorhydria the gastrin value falls within five to 15 minutes of intragastric instillation of hydrochloric acid. ${ }^{14}$ Likewise, in healthy subjects the intragastric administration of acid at the same time as a meal noticeably suppresses or abolishes the gastrin response to the meal. ${ }^{7}$ The lack of a fall in serum gastrin even three and a half hours after suppression of urease activity indicates that the hypergastrinaemia is unlikely to be caused by disruption of the acid inhibitory feedback mechanism by bacterial ammonia. We cannot, however, exclude the possibility that the degree of inhibition of urease activity with the acetohydroxamic acid might have been insufficient to allow restoration of the acid inhibitory mechanism.

We have previously reported that increasing $H$ pylori ammonia production threefold for four hours by intragastric infusion of urea does not raise serum gastrin. ${ }^{5}$ The present finding that inhibition of $H$ pylori ammonia production does not lower serum gastrin provides further evidence against the hypergastrinaemia being directly linked with bacterial urease activity.

Other mechanisms to explain the hypergastrinaemia need to be considered. It may be related to the chronic inflammatory cell infiltrate which the infection induces in the underlying antral mucosa where the $G$ cells are located. Studies using isolated perfused canine antrum have shown that the $\mathrm{T}$ lymphocyte products interleukin- 2 and $\gamma$ interferon stimulate gastrin release. ${ }^{15}$ Recent observations by Wyatt et al indicate that hypergastrinaemia correlates more closely with inflammation of the antral mucosa than with infection with $H$ pylori. ${ }^{16}$

This study also shows that normal urease activity is not essential for $H$ pylori to survive within the human stomach. It has been suggested that the organism produces ammonia in order to create an alkaline microenvironment and thus shield itself from the acidic gastric juice. ${ }^{17}$ In spite of considerable suppression of urease activity the infection was not cleared in any of our patients, as shown by the repeat breath test 10 days later. Ammonia production may be important in protecting the bacterium from luminal acid when the organism is first ingested but less important when the infection becomes established in the less acidic environment of the deep mucus layer.

We thank the staff of the Department of Nuclear Medicine who performed the ${ }^{14} \mathrm{C}$ urea breath test, Miss Susan Livingstone who performed the urea and ammonium assays, and Mrs Dorothy Ronney who typed the manuscript.

1 Oderda G, Vaira D, Holton I, Ainley C, Altare F, Ansaldi N. Amoxycillin plus tinidazole for Campylobacter pylori gastritis Amoxycillin plus tinidazole for Campylobacter pylori gastritis in children: assessment by serum Ig G antibod

2 McColl KEL, Fullarton GM, Nujumi AM, Macdonald AM, Brown IL, Hilditch TE. Lowered gastrin and gastric acidity after eradication of Campylobacter pylori in duodenal ulcer. Lancet 1989; ii: 499-500.

3 Levi S, Beardshall K, Swift I, Foulkes W, Playford R, Ghosh $\mathrm{P}$, et al. Antral Helicobacter pylori, hypergastrinaemia and duodenal ulcers: effect of eradicating the organism. $B M \mathcal{Y}$ 1989; 299: 1504-5.

4 Graham DY, Opekun A, Lew GM, Evans DJ, Klein PD, Evans DG. Ablation of exaggerated meal-stimulated gastrin release in duodenal ulcer patients after clearance of Helicorelease in duodenal ulcer patients after clearance of Helico-
bacter pylori infection. Am $\mathcal{F}$ Gastroenterol 1990; 85: 394-8.

5 Chittajallu RS, Neithercut WD, Macdonald AMI, McColl KEL. The effect of increasing Helicobacter pylori ammonia KEL. The effect of increasing Helicobacter pylori ammonia
production by urea infusion on plasma gastrin concentraproduction by urea infusion

6 Marshall $\mathrm{B}$, Langton $\mathrm{S}$. Urea hydrolysis in patients with Campylobacter pyloridis infection. Lancet 1986; i: $965-6$.

7 Walsh JH, Richardson CT, Fordtran JS. pH dependence of acid secretion and gastrin release in normal and ulce subjects. F Clin Invest 1975; 55: 462-8.

8 Lichtenberger LM, Nelson AA, Graziani LA. Amine trapping: physical explanation for the inhibitory effect of gastric acidity on the postprandial release of gastrin. Gastroenterology 1986; 90: 1223-31. 
9 Lichtenberger LM, Graziani LA, Dubinsky WD. Importance of dietary amines in meal-induced gastrin release. $A m$ Physiol 1982; 243: G341-7.

10 Williams JJ, Rodman JS, Peterson CM. A randomized doubleblind study of acetohydroxamic acid in struvite nephrolithiasis. N Engl F Med 1984; 311: 760-4.

11 Neithercut WD, Milne A, Chittajallu RS, El Nujumi AM, McColl KEL. The detection of Helicobacter pylori infection McColl KEL. The detection of Helicobacter pylon infection of the gastric mucosa by measurement of gastric aspirate

12 Feldman S, Putcha L, Griffith DP. Pharmacokinetics of acetohydroxamic acid. Preliminary investigations. Invest Urol 1978; 15: 498-500.

13 Levi S, Beardshall K, Haddad G, Playford R, Ghosh P, Calam
J. Campylobacter pylori and duodenal ulcers: the gastrin link. Lancet 1989; i: 1167-8.

14 Yalow RS, Berson SA. Radioimmunoassay of gastrin. Gastroenterology 1970; 58: 1-14.

15 Teichmann RK, Pratschke E, Grab J, Hammer C, Brendel W. Gastrin release by interleukin-2 and $\gamma$-interferon in vitro. Can 7 Physiol Pharmacol 1986; 64 (suppl): 62.

16 Wyatt JI, Rathbone BJ, Green DM, Primrose J. Raised fasting serum gastrin in chronic gastritis is independent of Campylobacter pylori status and duodenal ulceration. Gut 1989; 30: Al483.

17 Goodwin CS, Armstrong JA, Marshall BJ. Campylobacter pyloridis, gastritis and peptic ulceration. $\mathcal{F}$ Clin Pathol 1986; 39: $353-65$. 